\title{
Profile of Caesarian Section in Orotta Maternity Hospital.
}

\author{
Authors: Bereket Sebhatu MD' \\ Orotta National Referral Maternity Hospital \\ Asmara ,Eritrea \\ E-mail:warkamoy@yahoo.co.uk
}

Abstract

Maternal mortality has been steadily decreasing in Eritrea from estimates as high as 998 per 100,000 births in the 1995 survey to as low as 450 per 100,000 births in 2005. Delivering more women by caesarian section is one of the possible explanations that could have lead to this outcome. To examine the scientific plausibility of the practice of caesarian section in Eritrea, the practice of the procedure in the National Referral Maternity Hospital of Orotta was studied.

This study found that the rate of caesarian section (11.2\%), the indication of the procedure, the type of anesthesia used and the neonatal outcome was medically acceptable and comparable to international standards.

It is recommended that more women, particularly those who live in remote villages of Eritrea, should be provided with the opportunity of being delivered by caesarian sections to avoid obstetric morbidities like fistula and decrease maternal and neonatal mortality.

\section{Introduction}

Eritrea is a young State found in the Horn of Africa. Since it became independent from Ethiopia in 1991, it has faced many health challenges and maternal mortality is one. The ratio of maternal mortality has been declining steadily from estimates of 998/1000001 at the time of independence to near 450/100000 in 20052.One of the success tools in decreasing maternal mortality could be delivering more and more women by Caesarian Section.

Caesarian Section is the number one medical intervention attributed to the decrease in maternal mortality and morbidity. It is one of the best indicators for the quality of maternal health services offered in a country3. The safety of the operation has improved with time, as the surgical technique, the anesthetic technique and the availability of blood transfusion services improved.

Orotta Hospital is the National Referral Maternity Hospital where about $30 \%$ of the total facility based deliveries in Eritrea are conducted and where more than $60 \%$ the total Cesarean Section done in the country are performed4. Modern Obstetrics was being practiced in this hospital since the early 20th century during the Italian colonial era. Although the hospital has an excellent record system, very little of it was documented in a form of a research. Thus the objective of this study was:

1. To describe the practice of caesarian section in Orotta Hospital in terms of the rate of caesarian section, the indication of the caesarian section, the type of caesarian section, the mode of anesthesia used, the rate of post operative infection, the neonatal outcome and the maternal morbidity and mortality attributed to the procedure

2. To determine whether the practice of caesarian section in Orotta Hospital is within acceptable standards of contemporary obstetric practice elsewhere.

Materials and Methods

Information for the research was acquired using the following approaches.

1. Documenting records of total deliveries in general and the caesarian sections in particular from delivery records of Orotta Hospital5.

2. Using data from the Health Management Information System, MOH Eritrea. Decision Support System Database 20074.

3. Using the information of the day to day night duty reports of the hospital.

To identify the indications of caesarian section, the neonatal outcomes in terms of Apgar, types of anesthesia used, time of the operation and blood loss during the operation, a four month sample of the delivery record of the year 2007 was entered into an SPSS data file version 11 and analyzed accordingly. Medical and nursing students collected the data.

\section{Results}

The total deliveries in Orotta hospital during the year 2007 was 8293. Of these, 931 were delivered by caesarian section making the caesarian section delivery rate of the hospital $11.2 \%$ [95\% Cl $10.5-11.9 \%$ ]. During the same year, the hospital took care of $30 \%$ of the nationwide facility based deliveries and more than $60 \%$ of the caesarian deliveries.

All caesarian sections were a Transverse Lower Uterine Segment Section in type, although the abdominal wall incision varied from a majority of Transverse Suprapubic Incisions to occasional Longitudinal Lower Midline Incisions.

When stratified by whether the operations were Elective or Emergency (Non-elective) operations, 75.3\% of the operations in the hospital were emergency caesarian sections.

Spinal Anesthesia was used in $62 \%$ of the total Caesarian Sections. When the operations were stratified as Elective or Emergency procedure, Spinal anesthesia was used in $80.3 \%$ of the Elective and in $56 \%$ of the Emergency Operations (Table 1). 


\begin{tabular}{|c|c|c|c|}
\hline \multicolumn{4}{|c|}{$\begin{array}{l}\text { Table 1. Type of Anesthesia according to whether the } \\
\text { operation was an Elective or Emergency procedure }\end{array}$} \\
\hline \multirow[b]{2}{*}{ Operation } & \multicolumn{2}{|c|}{ Type of Anesthesia Used } & \multirow[b]{2}{*}{$\begin{array}{c}\text { Total } \\
\text { (percent) }\end{array}$} \\
\hline & $\begin{array}{l}\text { General } \\
\text { (Percent) }\end{array}$ & $\begin{array}{c}\text { Spinal } \\
\text { (percent) }\end{array}$ & \\
\hline Elective & $14(19.2)$ & $59(80.8)$ & $73(100)$ \\
\hline Emergency & $95(44.4)$ & $119(55.6)$ & $214(100)$ \\
\hline Total & 109 (38.0) & $178(62.0)$ & $287(100)$ \\
\hline
\end{tabular}

When APGAR was evaluated, $89 \%$ of the neonates born in the hospital rated 7 and above. There were 14 stillbirths among the emergency operations done in the hospital.

When blood lost per operation was compared, the mean blood lost was $433 \mathrm{ml}$, the mode was $300 \mathrm{ml}$ and the maximum blood lost was $1500 \mathrm{ml}$.

When the indication of the caesarian section was listed it was found that the proportions of indications of a Repeat Caesarian Section (20.9\%), Cephalo-pelvic Disproportion (17.4\%), Fetal Distress (14.3\%) and Prolonged Labor (for different causes) 912.2\%) were the first four commonest indications in the hospital. In total they accounted for $65 \%$ of the total indications (Table 2).

\begin{tabular}{|c|c|c|}
\hline $\begin{array}{l}\text { Table 2. Proportion of } \\
\text { according to the Indication }\end{array}$ & Caesari & Section \\
\hline $\begin{array}{l}\text { Indication for the } \\
\text { caesarian section }\end{array}$ & Count & Percent \\
\hline Previous caesarian section & 60 & $20.9 \%$ \\
\hline $\begin{array}{l}\text { Cephalo-pelvic } \\
\text { disproportion }\end{array}$ & 50 & $17.4 \%$ \\
\hline Fetal distress & 41 & $14.3 \%$ \\
\hline Prolonged labor & 35 & $12.2 \%$ \\
\hline Breech presentation & 34 & $11.8 \%$ \\
\hline Bad obstetric history & 13 & $4.5 \%$ \\
\hline Failed induction of labor & 11 & $3.8 \%$ \\
\hline Ante-partum hemorrhage & 13 & $4.5 \%$ \\
\hline Multi-fetal pregnancy & 4 & $1.4 \%$ \\
\hline $\begin{array}{l}\text { Pre-Eclampsia } \\
\text { and Eclampsia }\end{array}$ & 4 & $1.4 \%$ \\
\hline Miscellaneous & 22 & $7.7 \%$ \\
\hline Total & 287 & $100 \%$ \\
\hline
\end{tabular}

The rate of postoperative infection could not be given in numbers but no more than 1 patient per week had to return back to the hospital for a major infection.

\section{Discussion}

It is of important remark that Eritrea happens to be one of the first African countries were modern medical practice like caesarian section was being practiced as early as the beginning of the 20th century.
The rate of caesarian section delivery in Orotta National Referral Maternity Hospital during the year 2007 (11.2\%), is within the acceptable WHO recommended range of $5 \%$ to $15 \% 3$.

The type of anesthesia used, i.e. Spinal Anesthesia, in the majority of the patients, is also the recommended type of regional anesthesia in Caesarian Sections for its safety and simplicity.

When indications are considered the ranking of the indication is very similar to international standards6.

The 14 still births that occurred even if caesarian sections were performed could indicate that the procedure was not done on time and it is an area where corrective measures should be taken. The delay in the operation could either be a failure of the patient to come to the hospital early or delay in the care given. Yet the study did not investigate this issue.

When the general trend of the current practice of caesarian section procedure in the Orotta Maternity Hospital is compared with other standard hospital practices it can be accepted as medically reasonable4.

\section{Recommendation}

To decrease maternal and neonatal morbidity and mortality, it is recommended that a standard practice of Caesarian Section, such as that in Orotta maternity Hospital be provided to those women who deliver in areas outside the main capital city, Asmera. Thus, more physicians serving at the peripheral hospitals should be trained with the skill of caesarian section and the facilities they work in should be equipped with the necessary equipments.

\section{Acknowledgment}

I thank the staff of Orotta Maternity Hospital for the diligent care they gave to the women who became the subject of this study. My thanks also go to Dr Assefash Tsehaye for giving me a constant support during this study and who provided me with relevant reference materials. Last but not least, I thank the medical and nursing students who retrieved data from the delivery registry records and entered them into The SPSS program files.

\section{Reference:}

1. Eritrea Demographic and Health survey 1995. National Statistics Office. Department of Macro Policy and International cooperation. Office of the president. Eritrea \& DHS. Macro international. March 1997.

2. World Health Organization 2007. Maternal Mortality in 2005. Estimates developed by WHO, UNICEF, UNFPA, and The World Bank. Annex 3 p 24

3. UNICEF, World Health Organization, United Nations Population Fund. Guidelines for Monitoring the Availability and Use of Obstetric Services New York: United Nations Children's Fund, 1997:1-103.

4. Health Management Information System, MOH Eritrea. Decision Support System Database 2007

5. Delivery records of Orotta Referral Maternity Hospital

6. Natzan FC,Cnaltingus S, Bergsjo P, Cole S, Tueffel S, Ingenes L, Dalveit AK. Caesarian delivery in the 1980s; International comparison for indication. Am J Obstet Gynecol 170:495, 1994 